\title{
Owners' Perceptions Do Not Match Actual Ground-Dwelling Invertebrate Diversity in Their Gardens
}

\author{
Brigitte Braschler*(D), Valerie Zwahlen (D, José D. Gilgado, Hans-Peter Rusterholz and Bruno Baur \\ Section of Conservation Biology, Department of Environmental Sciences, University of Basel, St. Johanns-Vorstadt \\ 10, CH-4056 Basel, Switzerland; v.zwahlen@unibas.ch (V.Z.); josedomingo.gilgadohormaechea@unibas.ch (J.D.G.); \\ hans-peter.rusterholz@unibas.ch (H.-P.R.); bruno.baur@unibas.ch (B.B.) \\ * Correspondence: brigitte.braschler@unibas.ch
}

check for updates

Citation: Braschler, B.; Zwahlen, V.; Gilgado, J.D.; Rusterholz, H.-P.; Baur, B. Owners' Perceptions Do Not Match Actual Ground-Dwelling Invertebrate Diversity in Their Gardens. Diversity 2021, 13, 189. https://doi.org/ 10.3390/d13050189

Academic Editor: Michael Wink

Received: 26 March 2021

Accepted: 26 April 2021

Published: 29 April 2021

Publisher's Note: MDPI stays neutral with regard to jurisdictional claims in published maps and institutional affiliations.

Copyright: (c) 2021 by the authors. Licensee MDPI, Basel, Switzerland. This article is an open access article distributed under the terms and conditions of the Creative Commons Attribution (CC BY) license (https:// creativecommons.org/licenses/by/ $4.0 /)$.

\begin{abstract}
Urban gardens are important for human well-being, biodiversity and other ecosystem functions. Biodiversity-promoting initiatives would benefit from their owners being aware of the state of biodiversity in their gardens. We examined whether garden owners' perceptions match actual biodiversity in their gardens and whether perceptions are influenced by the owners' ecological knowledge. We used a structured interview to assess the motivations and biodiversity knowledge of owners of 33 domestic gardens in the city of Basel (Switzerland) and related them to a survey of native plants and several groups of ground-dwelling invertebrates in their gardens. Owners showed different priorities, with promotion of habitat for biodiversity, receiving, on average, higher scores than cultivation, recreation and garden designing. Owners prioritizing biodiversity promotion had gardens with high habitat richness. The garden owners' perceptions of both native plant and overall invertebrate diversity were not correlated with actual diversity data for native plants and ground-dwelling invertebrates. The perceptions of the abundance of invertebrate groups by garden owners with good biodiversity knowledge were not more accurate than those from owners with less knowledge. Despite their willingness, many owners do not know all the opportunities to promote biodiversity. Initiatives to further biodiversity-friendly gardening should thus transfer knowledge.
\end{abstract}

Keywords: ants; beetles; biodiversity; ecological knowledge; gastropods; millipedes; private domestic gardens; spiders; urbanization; woodlice

\section{Introduction}

Increasing urbanization is an important driver of environmental change and alters the functioning of ecosystem processes [1,2]. Worldwide, more and more people move to cities, with a projected population growth of 2.5 billion urban residents by 2050 [3]. Public green areas and domestic gardens provide important ecosystem services such as water storage, carbon sequestration, climate regulation (mitigating the urban heat island effect), improving air quality, habitat for plants and animals [4-8], recreation, increase human health and are of aesthetical value (e.g., [9-13]). In many cities, domestic gardens constitute a large proportion of green space [14]. Depending on the city, estimates of this proportion varied within the UK from 35\% for Edinburgh to 47\% in Leicester [15], and reached 36\% in Paris [16], while private patios made up to $86 \%$ of green area in León, Nicaragua [17]. This translates into considerable land cover even on a country scale. For example, in Switzerland, private gardens cover more than 1\% of total land area (see [18]). Furthermore, there is increasing evidence that the private gardens of a city taken together harbor significant shares of the countrywide biodiversity $[19,20]$. This is of particular importance in light of the dramatic biodiversity crisis, including insect decline [21-25].

In contrast to publicly managed urban green infrastructure, such as parks, embankments of traffic infrastructure and forests, private gardens are managed by a large variety of owners, which assign, depending on their motivation, different functions to their gardens $[26,27]$. Garden owners also show varied knowledge of biodiversity and its promotion, 
which most probably exceeds the variation among the professionals managing public green infrastructure [28]. Both the variation in aims and knowledge among garden owners result in a highly variable mosaic of differently managed garden areas, which in turn consist of a small-grained mosaic of patches of different habitat types [27]. This high habitat heterogeneity among and within gardens contributes to the overall high species richness in urban areas $[15,19,26,29]$.

The potential of private gardens for the promotion of biodiversity has been recognized [30,31]. Recently, various initiatives have been made to further ecological gardening [31-33]. However, biodiversity promotion in residential areas with urban private gardens requires the commitment of many owners from different backgrounds. The overall native species richness of a garden may be-at least partly-influenced by the motivation of the owner to promote native biodiversity given competing garden functions, his/her perception of the existing species richness and the owner's knowledge of ways to promote biodiversity.

The ability of laypersons to recognize species has been found to be limited, which might also hinder the perception of biodiversity [28]. An individual's perception of overall biodiversity is frequently based on the abundance of conspicuous taxa such as flowering plants, butterflies, birds and some small vertebrates (e.g., frogs, lizards, hedgehogs, squirrels) $[10,34,35]$. Similarly, studies of garden biodiversity have often focused on conspicuous groups including flowering plants, pollinators and birds (e.g., [30,36-38]) and did not consider small ground-dwelling invertebrates (see $[20,31,39,40])$. Numerous studies have shown that these proxies do not necessarily reflect overall biodiversity in open habitats including gardens $[20,35,41]$.

Self-reported assessments of species and habitat diversity by garden owners have been considered as a proxy in studies examining garden biodiversity $[18,42,43]$. For example, Young et al. [43] compared garden owners' assessments of plant species richness (horticultural cultivars and spontaneous native species combined) with survey data collected in the same gardens. They found a relatively high correlation between the two measures: $50 \%$ of the variation in plant species richness in gardens was explained by just two visual survey questions. Thus far, there is a gap in knowledge on how more cryptic taxa such as ground-dwelling invertebrates (e.g., millipedes, spiders, woodlice) are perceived by the general public. Most ground-dwelling invertebrates do not have interactions with specific plant species (i.e., they are not pollinators or specialized herbivores) and their diversity is thus less dependent on that of plants. Garden owners do not directly interact with or even promote ground-dwelling invertebrates in contrast to plants, including fruit trees, ornamental plants or vegetables, or pollinators such as bees and butterflies.

Thus, private gardens may play an essential role in native biodiversity conservation, but this relies on the owners' management, which at the same time might depend on the owners' perceptions and ecological knowledge and the main functions assigned to the gardens. Assessments of conspicuous taxa (e.g., flowering plants, butterflies and wild bees) made by owners have proven to be a useful proxy to estimate garden biodiversity [43], but the quality of such assessments has not been tested for less conspicuous taxa, which constitute the major proportion of the overall biodiversity. To our knowledge, it has never been tested whether garden owners' perceptions of their gardens' whole biodiversity are correlated with the diversity of non-conspicuous taxa such as ground-dwelling invertebrates. Neither has it been examined whether garden owners' knowledge of invertebrate diversity may influence their perceptions.

The aim of our study was to examine whether the biodiversity perception of garden owners, obtained through structured interviews, match actual diversity of ground-dwelling invertebrates and native plant species in their gardens recorded in extensive surveys by experts. We also evaluated the coarse biodiversity knowledge of the owners and asked for the main function assigned to the garden as both may affect their perceptions. We focused on private domestic gardens, excluding allotment gardens and community gardens. In particular, we addressed the following questions: (1) What are the garden owners' priorities 
concerning the use of their gardens? (2) How well do the garden owners' perceptions of biodiversity match the diversity of native plants and ground-dwelling invertebrates in their gardens? (3) Is the garden owners' knowledge of biodiversity and of means to promote it in their gardens correlated with the actual diversity recorded in these gardens?

\section{Materials and Methods}

\subsection{Garden Selection}

The study was conducted in the city of Basel, its suburbs and nearby villages in north-western Switzerland $\left(47^{\circ} 34^{\prime} \mathrm{N}, 7^{\circ} 36^{\prime} \mathrm{E}\right)$. In response to public calls in a municipal newspaper and in a newsletter, at a local conference, as well as through personal contacts of the authors, 65 garden owners or tenants (hereafter owners) offered access to their gardens for biodiversity assessments. After having visited all gardens in spring 2018, we chose 35 gardens that reflected a rural-urban gradient and represented both a range of garden sizes and different management types (little to intensively managed). The selected gardens belonged to four types of buildings: detached houses (no adjoining buildings; $n=13$ ), apartment blocks (several adjoining units on more than one level; $n=11$ ), semidetached houses (one adjoining building; $n=6$ ), and terraced (two or more adjoining buildings; $n=5$ ). The gardens considered in our study are representative for residential areas in Switzerland. They are representative of gardens managed directly either by the private owner or tenants with management rights. Similarly, based on our interactions during repeated visits for biodiversity surveys, we assumed owners and tenants of the 35 gardens being representative of this sector of society in Switzerland. Due to the overall low home ownership quotas among the general population in Switzerland, most of these owners and tenants belong to the middle class (including upper middle class). In summer/autumn 2018, we conducted an extensive biodiversity assessment in each garden (see below).

\subsection{Structured Interview with Garden Owners}

In August and September 2019, we conducted a structured interview with 33 of the garden owners to assess their decisions, goals and perceptions (two gardens were not considered as their users did not determine the garden's management). At the time of the interview, the detailed results from the biodiversity survey of their gardens had not been communicated to the owners. This was only carried out after the interview. This procedure avoided influencing garden owners' responses to the questions posed in the interview.

Garden owners were visited by appointment by two team members, already familiar to the interviewees from several visits during the biodiversity survey in the preceding year. Verbal consent was obtained for the interview. According to Swiss legislation, no ethics approval was required for the interviews as we did not collect information on the owners themselves but rather asked their perceptions of biodiversity. In many cases, several people are involved in the decision-making process regarding the management of a garden. These include couples, members of a family, inhabitants of shared dwellings, and members of several households having a joined garden. In these cases, the respective people could decide themselves who takes part in the interview. The interviewed person is referred to as an owner in this study. As an owner's socioeconomic details may not be representative of those of the whole group using the garden and for privacy reasons, we did not consider any socioeconomic factors such as gender, age, income, and educational attainment in this study.

The structured interviews were conducted by the same team member in all cases (B.Br), following a predefined list of questions (Table 1), with answers recorded by another team member (V.Z.). The questions were read to each interviewee in the same order, and when requested, further clarifications and explanations were provided. To facilitate answers and standardization, interviewees were asked to provide answers according to predefined ordinal scales for most questions (Table 1). This allowed collection of quantitative data, though we could not delve into the background of experience and opinions influencing these answers. For this reason, the introductory and concluding questions had open formats, 
allowing garden owners to speak about their motivations and ideas. The interviews lasted about half an hour each, though team members stayed available to answer the owner's questions about the project after each interview. Interviews were conducted between 5 August and 19 September 2019. The data set containing the responses to the questions is available in Table S1.

Table 1. Structured interview: Questions asked and categories of responses. All garden owners were interviewed by the same person (B.Br.). Garden owners were familiar with the interviewer due to the repeated visits for the biodiversity survey in the previous year.

\begin{tabular}{|c|c|c|}
\hline Question & Comment/Procedure & Types and Categories of Responses \\
\hline $\begin{array}{l}\text { 1. What does especially please you in } \\
\text { your garden? }\end{array}$ & $\begin{array}{l}\text { This open question at the beginning } \\
\text { allowed the interviewee to relax. The } \\
\text { answers were recorded and later } \\
\text { assigned to } 5 \text { categories. }\end{array}$ & $\begin{array}{l}\text { Five categories (subcategories): } \\
\text { (a) Naturalness/diversity } \\
\text { (natural/wild, high diversity, many } \\
\text { animals, trees) } \\
\text { (b) Health/wellness (nature } \\
\text { observation, working in the garden, } \\
\text { recreation/social activities, } \\
\text { landscaping) } \\
\text { (c) Cultivation } \\
\text { (flowers/fruit/vegetables) } \\
\text { (d) Design/beauty } \\
\text { (e) Size/structure }\end{array}$ \\
\hline
\end{tabular}

The interviewer named four groups of functions, one after one, and asked how important a particular group of functions is to the garden owner using a scale of 1 to 5, with (1) being not at all important, (2) being less important, (3) being of medium importance, (4) being important, and (5) being very important. Not all subfunctions of a function may occur in a given garden. In these cases, the garden owner was asked to evaluate the most frequently occurring subfunction within a group of subfunctions.

The garden owners were asked to express their estimates on a scale ranging from 1 to 5: (1) very low, (2) rather low, (3) moderate, (4) high, and (5) very high diversity.

The garden owners were asked to express their estimates on a scale ranging from 1 to 5: (1) very low, (2) rather low, (3) moderate, (4) high, and (5) very high diversity.
Groups of functions (subfunctions):

(a) Recreation (recre-

ation/eating/drinking/barbecue/play)

(b) Garden designing (remodeling of the garden for representative or aesthetic purposes)

(c) Cultivation (flowers/cultivation of fruits and vegetables)

(d) Biodiversity promotion (promotion of the habitat for native plants and animals) diversity of native plants in your garden to be?

4. How high do you estimate the diversity of invertebrates in your garden to be?
The interviewer read the groups-one after one-and the garden owners' observations were assigned to one of the following categories: (1) never seen, (2) rarely seen, (3) frequently (or abundant) seen and (4) I do not know the group. At that time, the interviewees did not know which of these groups we had surveyed in the gardens. Additional groups were added to acquire a proxy for interviewees' biodiversity knowledge (expressed by the number of "Do not know" responses).
Groups: ants, true bugs, beetles, butterflies, springtails, earwigs, spiders, harvestmen, centipedes/millipedes, slugs, snails, grasshoppers, woodlice, earthworms, other worms, ant lions, lacewings, horseflies 
Table 1. Cont.

\begin{tabular}{|c|c|}
\hline Question & Comment/Procedure \\
\hline $\begin{array}{l}\text { 6. Which of the following four factors } \\
\text { may influence the biodiversity in } \\
\text { your garden? }\end{array}$ & $\begin{array}{l}\text { The interviewer named four factors, one } \\
\text { after one, and asked the garden owner } \\
\text { about her/his assessment of the } \\
\text { importance of a particular factor for their } \\
\text { garden's biodiversity. The garden owner } \\
\text { could express her/his assessment using a } \\
\text { scale of } 1 \text { to } 5 \text {, with (1) no effect, (2) little } \\
\text { effect, ( } 3 \text { ) moderate effect, (4) strong } \\
\text { effect, and (5) very strong effect. The } \\
\text { effects could be positive or negative. }\end{array}$ \\
\hline
\end{tabular}

Types and Categories of Responses

Groups of factors:

(a) Type of garden management (including the decision not to manage something but let it grow wild)

(b) Size of the garden

(c) Location of the garden in relation to the city center (is it in the city center, or more towards the edge of the city in the suburbs)

(d) The adjacent gardens or forests/fields/meadows

Four categories:

(a) Improve habitat quality (wilder (less management), cat removal)

(b) Replace (invasive by native plants)

7. Do you see potential ways to increase the biodiversity in your garden further?
Open question to conclude the interview. The answers were recorded and later assigned to 4 categories. (c) Create (new habitats such as ponds or piles of stones, meadow with native flowers, provide additional resources incl. flowers, nesting and overwintering sites)

(d) No further measures needed (maximum biodiversity already achieved)

\subsection{Biodiversity Survey and Garden Characteristics}

The biodiversity survey was conducted on appointment during repeated visits in all participating gardens, which were evenly distributed from May to October in 2018. The garden owners gave verbal consent to the survey methods employed and times of visit, and in most cases remained present throughout the field survey. According to Swiss legislation, no field permit was required to collect invertebrates or plants on private ground in urban areas. In the biodiversity survey, we considered native plant species and seven groups of ground-dwelling invertebrates. The number of native plant species was thereby regarded as a surrogate of the naturalness of a garden. We recorded native plant species along transect lines proportional to the relative area of different habitat types (see [20]). We did not assess species richness of horticultural plants, as many of them are characterized by several varieties. This means that their diversity represents another taxonomical rank below species. However, we noted the presence of non-native invasive plant species [44].

The ground-dwelling invertebrate groups examined included phylogenetically distant taxa: Gastropoda (snails and slugs), Araneae (spiders), Diplopoda (millipedes), Isopoda (woodlice), Formicidae (ants), Carabidae (ground beetles), and Staphylinidae (rove beetles), excluding the subfamily Pselaphinae. None of the invertebrate groups is typically promoted on purpose by garden owners, or knowingly imported into gardens, thus allowing the use of our survey as an assessment of general biodiversity benefits of a garden owner's management decisions. In a few gardens, snails, slugs and ants were even managed as pest species. We used pitfall traps (small beakers with catching fluid, buried flush with the ground) and hay baits ( $25 \mathrm{~cm} \times 25 \mathrm{~cm}$ pockets of plastic net filled with wet hay) to sample all groups. Additional techniques were employed for snails and slugs (visual search and soil sieving) and millipedes and ants (visual search). Sampling was performed between 31 May and 18 October 2018 (for details see [20]). The collected individuals were determined at the species level by experts during the following months.

We found 173 native plant species in the 33 gardens examined. Altogether, we obtained 3181 individuals of snails and slugs (39 species), 3014 spider individuals (52 species), 
7834 woodlice individuals (10 species), 33 ground beetle individuals (20 species) and 1211 rove beetle individuals ( 85 species), 6373 millipede individuals (21 species) and ant individuals belonging to 28 species [20].

We assessed local garden characteristics that may affect a garden owner's perception of biodiversity: total garden area, area with vegetation, habitat type richness and structural diversity (a detailed description of the methods is given in [20]). As a surrogate for habitat type richness, we counted the presence of each of the following nine land cover types in each garden: grassland, tree, shrub, hedge, flower bed, vegetable bed, compost, dead wood, and a combined category for other structures (e.g., pile of stones, pond, nest box, bird feeder, nesting aids for insects).

As a measure of structural diversity of a garden, we calculated the Shannon diversity index for the height of plants. We measured the height of all shrubs and estimated the height of the trees (accuracy: $1 \mathrm{~m}$ ) using a measuring pole. The height of plants in the grassland area and in flower and vegetable beds was measured along a transect line for each habitat type separately. Transect lines ran along the long axis of the garden features. We considered plants at intervals of $2 \mathrm{~m}$ along the transect line. Sampling effort was thus proportional to the area with vegetation (see [20] for details). Data from the biodiversity surveys are presented in Tables S2 and S3.

\subsection{Analysis of the Structured Interview}

For illustration, the motivations, suggestions, and ideas from garden owners, which were given in response to the introductory and concluding open questions (Question 1 and Question 7), were assigned to five and four major categories, respectively, by the same two team members together. Garden owners were asked to answer Questions 2 to 6 on the given scale. For garden owners, the four functions of a garden (recreation, garden designing, cultivation, biodiversity promotion; see Table 1 for definitions of the garden functions) are not independent of each other. Therefore, we illustrated this dependency in the form of polygons displaying the relative significance of the four scores on different axes (Figure S1). To identify an owner's relative prioritization independent of the absolute values, we standardized scores by calculating the percentages of overall points scored by all four functions that were assigned to a specific function. In this way, an owner could signify priority for biodiversity promotion by saying this function was of medium importance to him if all three other functions were scored as even less important, while another owner assigning top scores to all four functions did not prioritize any of them over the others. We used this standardized priority score for the four functions (Question 2) to examine whether a garden owners' priorities were reflected in biodiversity outcomes, as assessed in our field survey using Spearman rank correlations (biodiversity outcomes measured habitat type richness, structural diversity, species richness of different taxonomic groups). In a similar way, we assigned standardized scores to the four possible influences (garden management, garden size, location of garden, adjacent habitats) on a garden's measured biodiversity in Question 6. We used Spearman rank correlation to examine whether standardized scores of garden management (Question 6) and biodiversity promotion (Question 2) are correlated. The associations between priorities assigned to the garden functions and actual species richness and abundance were tested using Welch's unequal variances $t$-test. If data were not normally distributed even after transformation, Wilcoxon tests were used instead (for details, see Table S4).

We used Spearman rank correlations to examine whether the garden owners' perceptions of native plant and invertebrate richness correlate with actual data of our respective field survey (Question 3 and Question 4). Actual data from the survey showed that habitat richness is correlated with native plant and invertebrate richness in the gardens investigated and thus may serve as a proxy for species richness. We used Spearman rank correlation to examine whether garden owners' perceptions of native plant and invertebrate richness were correlated with actual data on habitat richness and structural diversity of the vegetation (Question 3 and Question 4). 
We examined owners' coarse knowledge of biodiversity by asking them whether they recognized 18 different invertebrate groups such as spiders or lacewings usually present in gardens, including those groups assessed in our field survey (Question 5; see Table 1). We expressed the frequencies of "do not know" for each group as percentages to examine which groups are widely known. Hereafter, we considered owners who recognized at least 16 out of the 18 invertebrate groups as having good biodiversity knowledge. For the groups recognized by the owner, we also asked for their estimate of abundance of these groups in their gardens in three coarse categories (Question 5; Table 1). For invertebrate groups investigated in the field survey, we examined potential associations between the garden owners' estimate of the groups' abundance with measured abundance data using Kruskal-Wallis tests or Wilcoxon signed rank test (for those groups where only the two categories "rare" and "abundant" were mentioned). Garden owners, who did not recognize a particular group, were omitted from the respective analysis. These analyses were repeated using only estimates from garden owners with good biodiversity knowledge (see above).

\section{Results}

\subsection{Gardens Provide Different Sources of Joy to Owners (Question 1 from the Interview)}

When asked what about their gardens brought them most joy, the interviewees most frequently mentioned functions relating to either the categories health/wellness or naturalness/diversity (Figure 1). Health/wellness included in this order nature observation (e.g., bird watching and feeding), working in the garden, recreation and social aspects, and the freedom to implement their ideas of garden design (Figure 1). Naturalness/diversity included in this order a natural/wild habitat, high diversity of visible organisms, high abundance of diverse animals, and presence of trees (Figure 1). Less often mentioned were functions relating to cultivation (flowers, fruit, vegetables), design/beauty and the size/structure of the garden (Figure 1).

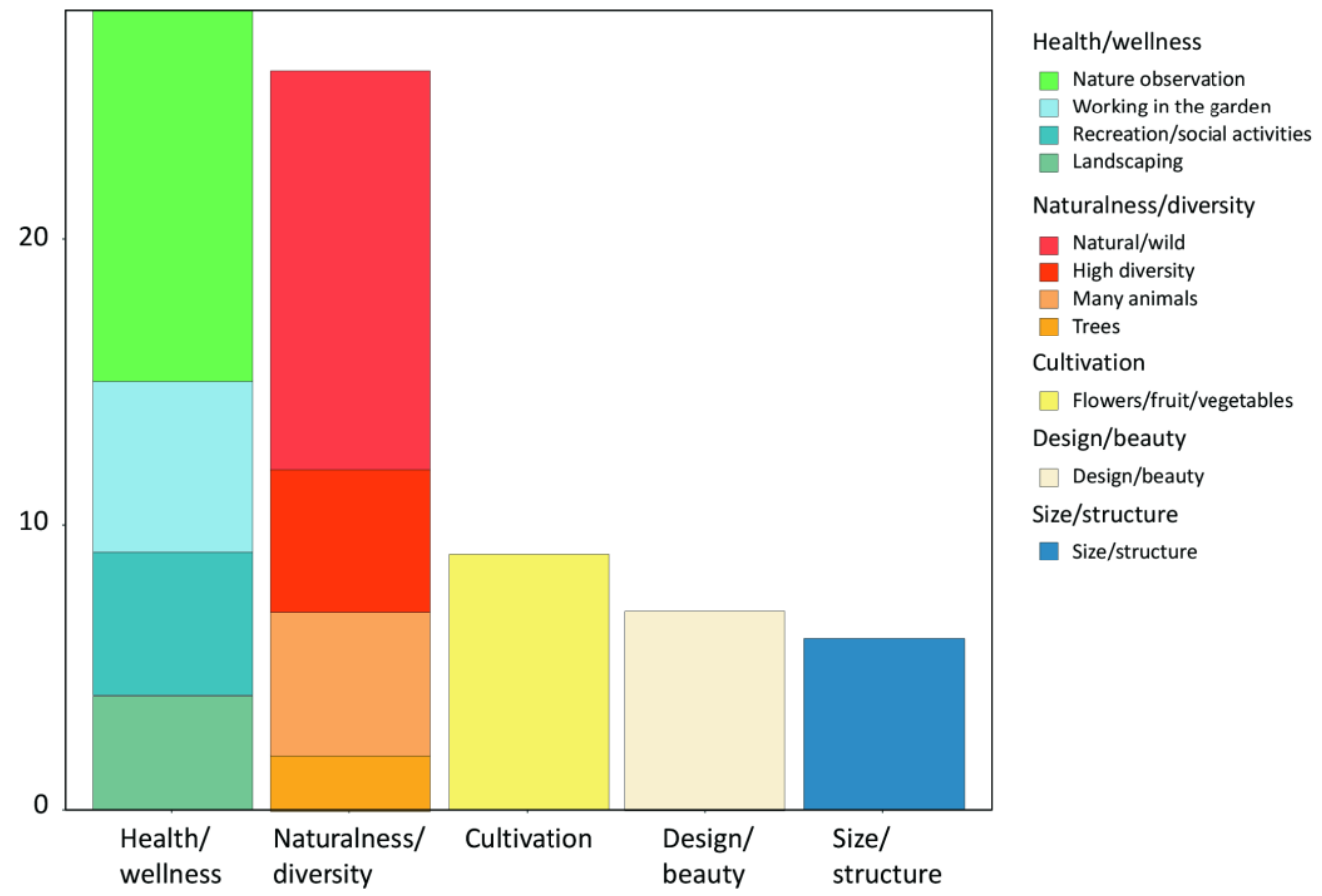

Figure 1. Gardens provide different sources of joy to owners. Responses to the open question "In your garden: What does especially please you?" by interviewed garden owners. Multiple answers were allowed. Answers were later assigned to five main categories. Note that activities including nature observation (bird watching) were considered as belonging to the health/wellness category. 


\subsection{Garden Owners' Priorities and Resulting Garden Management (Question 2)}

When asked about the four possible main functions of their gardens (recreation, garden designing, cultivation, biodiversity promotion), garden owners exhibited different priorities both within and among functions. Overall, biodiversity promotion received the highest scores (mean: 4.5 ; range: $2-5$ ), followed by cultivation $(4.2 ; 2-5)$, recreation $(3.8$; $1-5)$, and garden designing (3.6; $1-5$; in all cases $n=33$ ). Despite this overall order of priority, there was a large variation in priority within functions, with each function given the highest score by some owners, while being considered of low importance by others (Figure S1). The order of function prioritization is retained when standardized scores are considered.

\subsection{Main Aim of Gardens and Actual Biodiversity (Question 2)}

Considering standardized scores, gardens whose owners had assigned higher priority to promoting habitats for biodiversity indeed had higher habitat richness than gardens receiving lower priority in this respect $\left(R_{s}=0.38, n=33, p=0.031\right)$. Similarly, gardens whose owners prioritized cultivation tended to have higher habitat richness than those of owners who assigned relatively lower priority to this function $\left(R_{s}=0.31, n=33, p=0.076\right)$. In contrast, gardens whose owners had assigned high priority to garden designing had lower habitat richness than those of owners who did not prioritize this function $\left(R_{s}=-0.46\right.$, $n=33, p=0.007)$. Structural diversity of the vegetation, another measure of habitat diversity, was not correlated with any of the priority scores.

Considering actual species richness data, gardens whose owners gave a high priority to habitat promotion tended to harbor more woodlice species (Table S4). Interestingly, gardens whose owners gave a high priority to recreation harbored marginally significantly higher native plant species richness than gardens with a low priority assigned to recreation ( $p=0.057$; Table S4). Gardens whose owners assigned a higher priority to the cultivation of flowers, fruits or vegetables contained more spider individuals than gardens whose owners did not assign a high priority to this function ( $p=0.004$; Table S4). In contrast, the priority assigned to garden designing had no relationship with actual species richness or abundance (Table S4).

\subsection{Garden Owners' Perceptions of the Biodiversity in Their Gardens (Questions 3 and 4)}

Most garden owners stated that their gardens harbored moderate to very high species richness of native plants and invertebrates (Figure 2). The garden owners' perceptions of plant diversity were not correlated with actual data from the survey $\left(R_{s}=0.22, n=33\right.$, $p=0.22$ ). Similarly, their perceptions of invertebrate diversity were not correlated with the actual diversity of the ground-dwelling invertebrates examined $\left(R_{s}=0.15, n=33\right.$, $p=0.40)$. Interestingly, the garden owners' perceptions of native plant and invertebrate species richness were highly correlated $\left(R_{s}=0.46, n=33, p=0.0078\right)$. Furthermore, the garden owners' perceptions of plant diversity were correlated with the actual species richness recorded (native plants and all ground-dwelling invertebrate groups examined combined; $\left.R_{S}=0.36, n=33, p=0.0451\right)$ and with the species richness of all ground-dwelling invertebrate groups examined combined $\left(R_{s}=0.44, n=33, p=0.0115\right)$.

Our biodiversity survey data indicated that habitat type richness in the gardens investigated can be considered as a proxy for both native plant and ground-dwelling invertebrate species richness (native plant richness: $R_{s}=0.40, n=33, p=0.0199$; invertebrate richness: $R_{s}=0.36, n=33, p=0.0406$ ). However, garden owners' perceptions of native plant and invertebrate species richness were neither correlated with the measured habitat type richness nor with the structural diversity of the vegetation (all $p>0.09$ ). An exception was the garden owners' perceptions of invertebrate richness, which were correlated with measured structural diversity $\left(R_{s}=0.36, n=33, p=0.0376\right)$. 

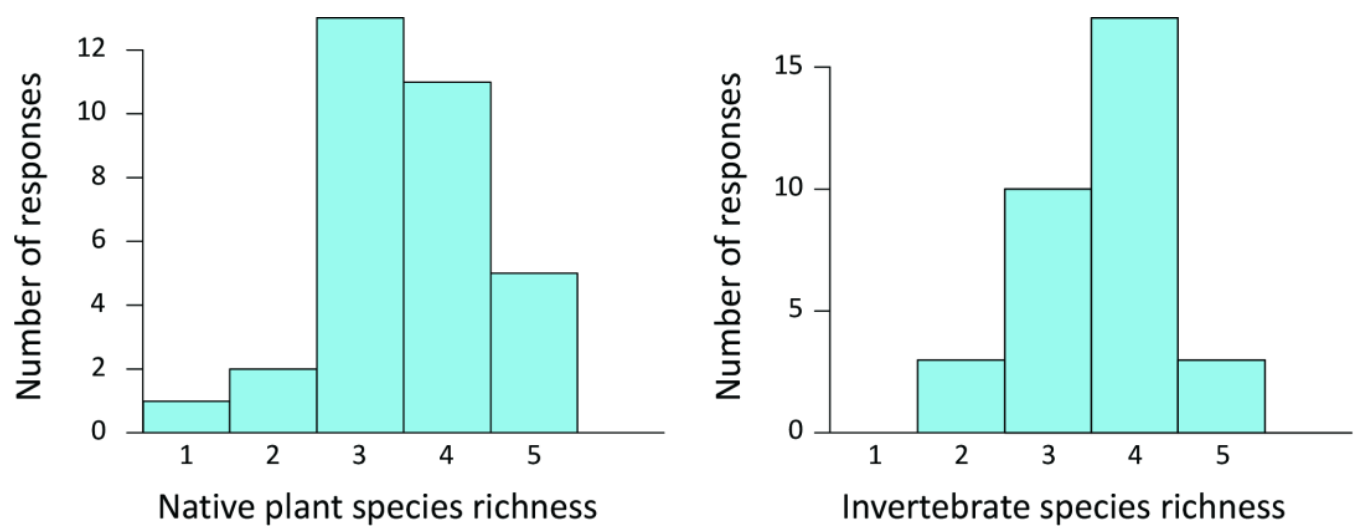

Figure 2. Garden owners' perceptions of species richness in their gardens. Responses to the questions "How high do you estimate the diversity of native plants in your garden to be?" and "How high do you estimate the diversity of invertebrates in your garden to be?" by interviewed garden owners. Answers were given on a scale ranging from 1: "very low" to 5: "very high". One owner did not rate plant richness.

\subsection{Garden Owners' Knowledge on Diversity of Invertebrates (Question 5)}

The garden owners' knowledge on different taxonomical groups varied widely. Only one garden owner recognized all 18 invertebrate groups asked about, while four garden owners did not recognize seven of the groups and one even failed to recognize eight of the groups. Springtails were the least recognized group (24 times not recognized, 73\%), followed by "other worms, excluding earthworms" (55\%), lacewings (39\%), ant lions (30\%), and harvestmen (27\%) (Table S5).

\subsection{Garden Owners' Perceptions of the Abundance of Different Invertebrate Groups (Question 5)}

Garden owners' estimates of the abundance of common invertebrate groups (number of individuals of ants, beetles, centipedes and millipedes, snails, slugs, spiders or woodlice; in three coarse categories) in their gardens were not related to measured abundances from the survey (Kruskal-Wallis or Wilcoxon ranked sign tests; $p>0.24$ for all groups, except slugs with $p=0.067)$. Repeating these analyses for garden owners with good biodiversity knowledge separately (for definition see methods) did not change these findings ( $p>0.32$ for all groups).

\subsection{Garden Owners' Assessments Regarding Key Factors Affecting the Biodiversity in Their Gardens (Question 6)}

Asked about the importance of four factors that may affect the biodiversity of their gardens (type of management, size of garden, location of garden, adjacent habitats), garden owners varied both in how important they rated each potential factor and in the relative ranking of those factors. Overall, the only factor directly under control of the owners, the type of management, received the highest scores (mean: 4.5; range: 2-5). Location of the garden was rated next in importance $(4.0 ; 1-5)$, while garden size and adjacent habitats were considered less important $(3.5 ; 1-5$ for both; in all cases $n=33)$. Despite this overall ranking, there was a large variation in priority within factors, with each factor given the highest possible score by some owners, while being considered of low importance by others. The order of the factors' importance is similar when standardized scores are considered (type of management: $29.1 \%$ (17.6-38.5\%), location of the garden: $25.9 \%(7.7-36.4 \%)$, size of garden: $22.7 \%$ (9.1-31.3\%), adjacent habitats: $22.3 \%(7.1-38.5 \%) ; n=33$ in all cases).

There was a slight trend for the importance they assigned to management to be correlated with that they assigned to biodiversity promotion (score from Question 2; Spearman rank correlation: $R_{s}=0.32, n=33, p=0.069$ ). However, when taking other options into account, there was no correlation between the relative importance the owners 
assigned to the factor "type of management" and the function "biodiversity promotion" (Spearman rank correlation on standardized scores: $R_{s}=-0.04, n=33, p=0.84$ ).

\subsection{Owners' Suggestions on Promoting Biodiversity in Their Gardens (Question 7)}

When asked about potential improvements for their gardens, $68 \%$ of the owners suggested creating new habitat types such as extensively managed meadows with flowers, piles of stones, or ponds and structures to provide food or overwintering sites (Figure 3). Twenty-four percent suggested replacing non-native plants with native ones, and improving existing habitats-e.g., by removing domestic cats (Figure 3). Gardens whose owners suggested improvements did not differ in species richness of native plants and invertebrates from those gardens for which no improvements were suggested (Fisher's exact test: native plant species richness: $p>0.99$; invertebrate species richness: $p=0.39$ ).

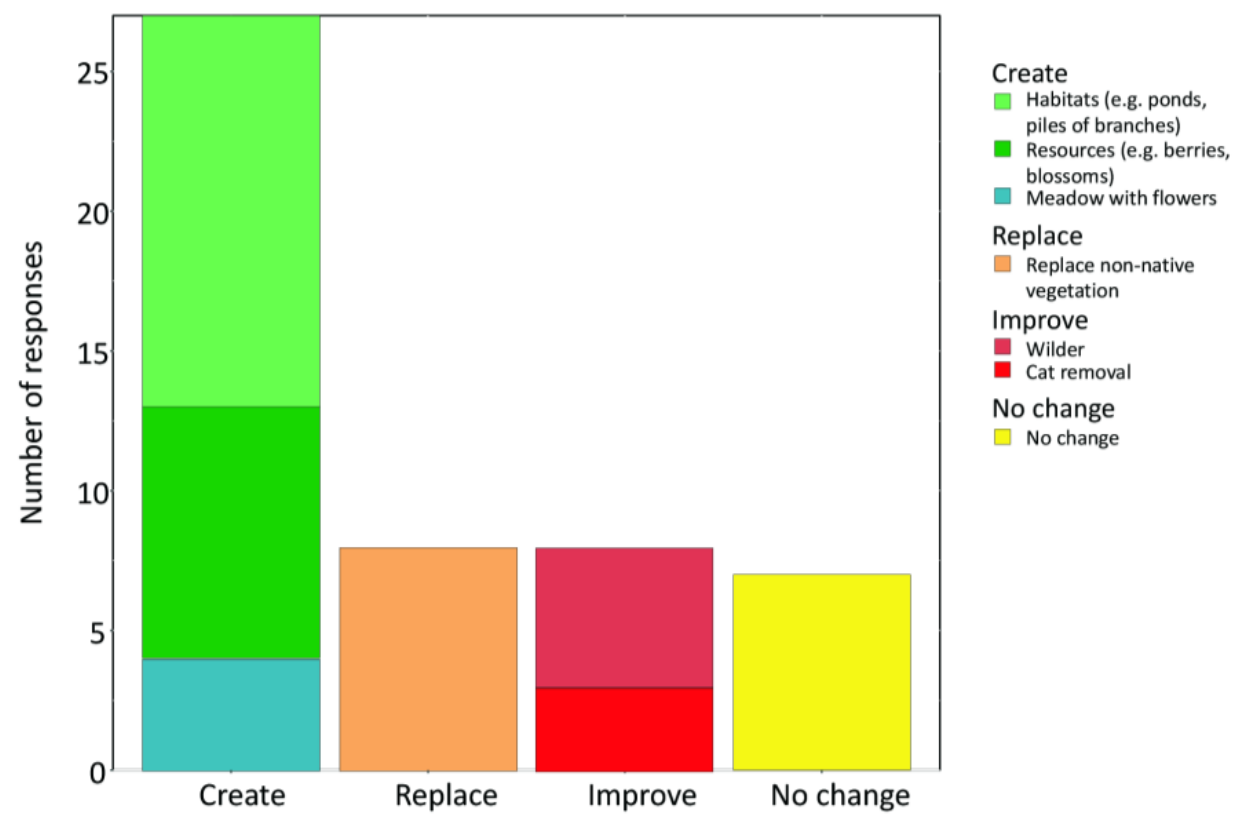

Figure 3. Owners' suggestions on how to further promote biodiversity in their gardens. Answers to the open question "Do you see potential ways to increase the biodiversity in your garden?" by interviewed garden owners. Multiple answers were allowed. Answers were later assigned to four main categories.

Twenty-one percent of the owners stated that their garden has already achieved the maximum possible biodiversity taking into account other functions of the garden (such as use for recreation or cultivation) and local conditions and that therefore no further improvement is necessary (Figure 3). The latter indicates reduced awareness by a significant proportion of the garden owners of the potential to remove or replace non-native invasive vegetation present, as at least one invasive plant species was recorded in $71 \%$ of those gardens. A similar proportion of owners, who suggested improvements, also had invasive plant species in their garden $(85 \%)$. There was no significant effect of the presence or absence of invasive plants in the gardens on the likelihood that owners suggested any type of management to improve biodiversity outcomes (Fisher's exact test, $p=0.59$ ). Indeed, overall, only eight out of the 27 garden owners with at least one invasive plant species in their garden suggested replacement of non-native vegetation with native vegetation (30\%), markedly less than the share of owners that suggested creating various new habitats (19 of $33 ; 58 \%)$.

\section{Discussion}

In our study, owners differed widely in both priorities for the functions of their gardens and the knowledge of native biodiversity and its promotion. While garden owners' 
perceptions of both native plant and invertebrate species richness were not correlated with actual data for native plant species richness and the richness of ground-dwelling invertebrates, their perceptions of plant diversity were correlated with actual data on ground-dwelling invertebrate species richness.

The gardens considered in our study represent a typical range in both size and naturalness of urban and suburban gardens of a central European city [43]. Most of these cities are comparatively old and thus compact in layout, limiting the potential garden size in the city center. Though rising, in Switzerland the percentage of home ownership (26\%) is relatively low due to high land and construction prices and particularities in the Swiss tax code and in regulations when compared with the proportion of ownership in other European countries, ranging from 53\% in Germany to $96 \%$ in Romania in 2014 [45,46]. In our study, however, all persons interviewed could participate in decision-making on the garden management, sometimes after originally obtaining permission from their landlords and neighbors. We assume that the persons interviewed are representative of Swiss private garden owners and tenants.

Our garden owners gain multiple benefits from their gardens, including opportunities for activities (e.g., sport, working in the garden, play) as well as experiences (e.g., nature observation, social events), although to different extents. Some spend several hours a day gardening (a significant part of their wellness and health regime), while others use their garden more sporadically (fine weather, social events) (anecdotal reports by garden owners). The owner-specific priorities expressed in Questions 1 and 2 in the interviews reflect this variation. Surprisingly, functions related to naturalness and biodiversity were almost equally frequently mentioned as those related to health/wellness as providers of joy, far outclassing functions related to production or aesthetics.

Owners use different parts of their gardens in different ways. Recreational activities such as outdoor dining, socializing and playing mainly take place on intensively managed lawns close to the building, while biodiversity promotion or cultivation of flowers and vegetables happens in different specialized parts of the garden. All this results in a finegrained mosaic of very different habitat patches even within a single garden. This high variety in habitat types is reinforced by differently managed adjacent gardens, leading to an area that has high potential to harbor many different native species with varying habitat requirements [27]. However, the management of domestic gardens is in the hands of owners and tenants with varying interests [5,27], and thus of people, who, as our study showed, are often only partially able to recognize the native species diversity. On the scale of neighborhoods, the management of private urban green space is divided among many owners, each responsible for only a small patch [27]. This challenges the overall target to increase biodiversity in this part of the urban green areas, though some options through legislation (e.g., limiting pesticide use, banning non-native invasive species) and community and NGO initiatives exist (e.g., communal composting, local markets for native plants). Even if these attempts initially only reach a relatively small proportion of owners, they will prove effective in providing resources for biodiversity scattered within the urban landscape [27]. Furthermore, the "pioneers" will serve as conduits of knowledge to neighbors, thus incentivizing them to join the effort. However, if owners, as shown in our study, perceive native biodiversity incorrectly, they may be prone to selecting the wrong management techniques for their biodiversity promotion goals [10].

Even though many owners are highly motivated to promote biodiversity, their knowledge on invertebrate groups, the overall native species richness in their gardens and the potential for improving habitats should be improved. Garden owners frequently interact with almost all plants (either by promoting or removing them) but with few invertebrates outside of pest control management. In consequence, most of them likely intuitively equate biodiversity with the richness of blooming plants (including horticultural varieties), the presence of mammals (e.g., hedgehogs, squirrels), and the abundance of birds, butterflies and bees; all conspicuous and colorful species. The species richness of these groups does not necessarily correlate with overall biodiversity, which is largely determined by more 
cryptic small organisms (invertebrates, mosses, algae). However, these overlooked groups are essential for maintaining a multitude of ecosystem services in urban areas (e.g., litter decomposition [47-49], soil aeration [50], nutrient recycling [51]). Nonetheless, owners were able to perceive some aspects of biodiversity in their gardens, which were correlated with the diversity of the ground-dwelling invertebrate fauna surveyed in our study.

Our analyses suggested that owners perceived structural diversity of their garden. This may have indirectly influenced their assessment of invertebrate diversity, as structural diversity is of importance for bees and butterflies [52]—-both conspicuous groups that were not assessed in our survey. However, our actual field survey data showed that structural diversity was not a suitable proxy for ground-dwelling invertebrate diversity in these habitats. Similarly, the garden owners' perceptions of native plant diversity reflected the actual species richness of ground-dwelling invertebrates in their gardens. As their perceptions of native plant species richness, however, were not correlated to actual native plant species richness recorded in their gardens, we assumed that they instead perceived a proxy related to vegetation structure or resource abundance, which was correlated with ground-dwelling invertebrate richness. These details of individual perception need further investigation to understand their effect on garden management.

The provision of aesthetic beauty is another component of ecosystem services [34,53-55]. People's aesthetic appreciation of biodiversity could be influenced by both the actual and the perceived species richness of habitats $[34,55]$. In this context, it is important to determine how well people are able to perceive species richness in human-managed habitats $[10,34,42,56]$, including private gardens. In our study, the aesthetical aspect was not considered.

Our study also indicated that while a number of the garden owners were aware of the problems caused by non-native invasive species, they frequently could not identify them correctly even if present in their garden. Similarly, when interacting with garden owners, we concluded that many did not differentiate between native plants and their horticultural varieties. This may partly explain why garden owners' perceptions of native plant diversity were not correlated with actual data of native plant species richness in their gardens, as the owners will have been misled by the diversity in flower colors [35].

Our sample of garden owners may be slightly biased towards those interested in the nature in their garden, as people without interest in what lives in their gardens would have been less likely to volunteer their gardens for the biodiversity survey. Improvement of general biodiversity knowledge in the population is the key to promoting species richness in urban gardens and to improving the ecosystem services the species provide. This is underlined by our study showing that even those garden owners with relatively better biodiversity knowledge still have limits on how they estimate the overall biodiversity in their gardens. Initiatives to promote knowledge could include outreach efforts, such as regular blogs on particular native species that can occur in gardens. Another promising means would be public excursions in the community and public talks centered on garden biodiversity and its promotion. An important role could be played by schools, as teachers have been shown to greatly influence biodiversity recognition skills in their pupils [57]. School gardens could contribute by teaching biodiversity-friendly gardening.

When asked about the potential impact of four different factors on biodiversity in their gardens, owners rated their garden management the highest, assigning lower influence to the outside factors such as location of garden and adjacent habitats, as well as to garden size. This feeling of being able to make a difference in supporting nature may increase engagement, which would be advantageous for biodiversity promotion initiatives relying on participation by garden owners. Indeed, this perception of influence of garden management is partly supported through our earlier work, which showed that local garden characteristics influenced the species richness or abundance of some invertebrate groups [20]. On the other hand, location (distance to the city center), adjacent habitats (percentage of green area) and garden size proved to be even more influential for grounddwelling invertebrate diversity in the gardens examined [20]. 
When asked about potential improvements for their gardens, an overwhelming majority of garden owners saw at least one opportunity to further promote native biodiversity in their gardens. However, $21 \%$ of owners stated that no further improvement for biodiversity promotion is possible in their garden, given constraints to other functions such as recreation and cultivation. This lack of ideas may be partly due to gaps in their biodiversity and management knowledge as they overlooked opportunities that would not clash with other uses of the garden. For example, even though many of their gardens had invasive plant species on their grounds, the owners did not suggest replacing them with native species (Figure 3). In several gardens, borders were marked with hedges of the invasive non-native cherry laurel (Prunus laurocerasus). Replacing them with native species, e.g., privet (Ligustrum vulgare), would not imperil the function of the hedge.

\section{Conclusions}

Our study showed that garden owners' perceptions of the diversity of their gardens give limited information on the actual diversity of native plants and ground-dwelling invertebrates within those gardens. Furthermore, owners differed widely in biodiversity knowledge and knowledge of ways to promote biodiversity. Private domestic gardens have high potential to support urban biodiversity and to provide ecosystem services and many owners are motivated to contribute to the effort. However, to optimize gardens for biodiversity, many owners may benefit from assistance to limit missed opportunities due to gaps in ecological knowledge. Various means of knowledge transfer may contribute to this target, including leaflets, local demonstrations on biodiversity-friendly gardening for homeowner associations, skill and information transfer in local markets for native plants, and lessons on gardening and species determination in schools.

Previous biodiversity assessments in private gardens have mainly focused on flowering plants and conspicuous taxa such as pollinators (butterflies, bees) or birds. However, many ecosystem services (e.g., decomposition, nutrient cycling) are provided by less noted small invertebrates that are generally not promoted on purpose by garden owners. In our study, these less studied organisms were considered as surrogates for biodiversity. Our approach of combining results from an in-depth biodiversity survey with structured interviews of the people responsible for garden management offered the opportunity to directly relate biodiversity outcomes to motivations and ecological knowledge.

Supplementary Materials: The following materials are available online at https: / www.mdpi.com/ article/10.3390/d13050189/s1, Figure S1: Importance assigned to four functions by garden owners, Table S1: Responses by garden owners to the questions outlined in Table 1 assigned to different categories for data analysis, Table S2: Environmental variables of the gardens examined, Table S3: Species richness and abundance of the groups examined in the biodiversity survey, Table S4: Priority scores assigned by garden owners to four garden functions in association with species richness and abundance of different invertebrate groups and native plants assessed in the field survey, Table S5: Garden owners' knowledge about the diversity of different invertebrate groups in their gardens.

Author Contributions: Conceptualization, B.B. (Brigitte Braschler), V.Z., J.D.G., H.-P.R. and B.B. (Bruno Baur); data curation, B.B. (Brigitte Braschler); formal analysis, B.B. (Brigitte Braschler) and B.B. (Bruno Baur); funding acquisition, J.D.G. and B.B. (Bruno Baur); investigation, B.B. (Brigitte Braschler), V.Z., J.D.G., H.-P.R. and B.B. (Bruno Baur); methodology, B.B. (Brigitte Braschler), V.Z., J.D.G., H.-P.R. and B.B. (Bruno Baur); supervision, H.-P.R. and B.B. (Brigitte Braschler); visualization, B.B. (Brigitte Braschler); writing-original draft, B.B. (Brigitte Braschler) and B.B. (Bruno Baur); writing - review and editing, B.B. (Brigitte Braschler), V.Z., J.D.G., H.-P.R. and B.B. (Bruno Baur). All authors have read and agreed to the published version of the manuscript.

Funding: This research was partly funded by the Basler Stiftung für experimentelle Zoologie.

Institutional Review Board Statement: Ethical review and approval were waived for this study, as Swiss legislation does not require ethics approval for interviews as long as no personal information was recorded from the owners themselves. We only asked for their perceptions of biodiversity and did not relate this information to socioeconomic data. No maps or addresses are provided in this 
study or associated data files that would allow identification of the investigated gardens. Data from the study are stored anonymously with the separate gardens indicated by a code not identifying information in accordance with the guidelines provided by the Declaration of Helsinki.

Informed Consent Statement: Informed consent was obtained from all subjects involved in the study. Data Availability Statement: All data are presented in this study and Supplementary Tables S1-S5.

Acknowledgments: We thank the owners for allowing us to access their gardens for this study and agreeing to be interviewed. We thank S. Buchholz and two anonymous reviewers for comments on the manuscript.

Conflicts of Interest: The authors declare no conflict of interest. The funders had no role in the design of the study; in the collection, analyses, or interpretation of data; in the writing of the manuscript, or in the decision to publish the results.

\section{References}

1. Kowarik, I. Novel urban ecosystems, biodiversity, and conservation. Environ. Pollut. 2011, 159, 1974-1983. [CrossRef] [PubMed]

2. Ziter, C. The biodiversity-ecosystem service relationship in urban areas: A qualitative review. Oikos 2016, 125, 761-768. [CrossRef]

3. United Nations General Assembly. The New Urban Agenda; United Nations: New York, NY, USA, 2016; Available online: habitat3.org/the-new-urban-agenda/ (accessed on 23 March 2021).

4. Salako, V.K.; Fandohan, B.; Kassa, B.; Assogbadjo, A.E.; Idohou, A.F.R.; Gbedomon, R.C.; Chakeredza, S.; Dullo, M.E.; Kakaï, R.G. Home gardens: An assessment of their biodiversity and potential contribution to conservation of threatened species and crop wild relatives in Benin. Genet. Res. Crop Evol. 2014, 61, 313-330. [CrossRef]

5. Aronson, M.F.; Lepczyk, C.A.; Evans, K.L.; Goddard, M.A.; Lerman, S.B.; MacIvor, J.S.; Nilon, C.H.; Vargo, T. Biodiversity in the city: Key challenges for urban green space management. Front. Ecol. Environ. 2017, 15, 189-196. [CrossRef]

6. Ives, C.D.; Gordon, A.; Oke, C.; Raymond, C.M.; Hehir, A.; Bekessy, S.A. Spatial scale influences how people value and perceive green open space. J. Environ. Plan. Manag. 2018, 61, 2133-2150. [CrossRef]

7. Jokimäki, J.; Suhonen, J.; Kaisanlahti-Jokimäki, M.L. Urban core areas are important for species conservation: A European-level analysis of breeding bird species. Landsc. Urban Plan. 2018, 178, 73-81. [CrossRef]

8. Melliger, R.L.; Braschler, B.; Rusterholz, H.-P.; Baur, B. Diverse effects of degree of urbanization and forest size on species richness and functional diversity of plants, and ground surface-active ants and spiders. PLoS ONE 2018, 13, e0199245. [CrossRef]

9. Fuller, R.A.; Irvine, K.N.; Devine-Wright, P.; Warren, P.H.; Gaston, K.J. Psychological benefits of greenspace increase with biodiversity. Biol. Lett. 2007, 3, 390-394. [CrossRef]

10. Dallimer, M.; Irvine, K.N.; Skinner, A.M.; Davies, Z.G.; Rouquette, J.R.; Maltby, L.L.; Warren, P.H.; Armsworth, P.R.; Gaston, K.J. Biodiversity and the feel-good factor: Understanding associations between self-reported human well-being and species richness. BioScience 2012, 62, 47-55. [CrossRef]

11. Andersson, E.; Tengö, M.; McPhearson, T.; Kremer, P. Cultural ecosystem services as a gateway for improving urban sustainability. Ecosys. Serv. 2014, 12, 165-168. [CrossRef]

12. Carrus, G.; Scopelliti, M.; Lafortezza, R.; Colangelo, G.; Ferrini, F.; Salbitano, F.; Agrimi, M.; Portoghesi, L.; Sernenzato, P.; Sanesi, G. Go greener, feel better? The positive effects of biodiversity on the well-being of individuals visiting, urban and peri-urban green areas. Landsc. Urban Plan. 2015, 134, 221-228. [CrossRef]

13. Soga, M.; Gaston, K.J.; Yamaura, Y. Gardening is beneficial for health: A meta-analysis. Prev. Med. Rep. 2017, 5, 92-99. [CrossRef] [PubMed]

14. Dewaelheyns, V.; Rogge, E.; Gulinck, H. Putting domestic gardens on the agenda using empirical spatial data: The case of Flanders. Appl. Geogr. 2014, 50, 132-143. [CrossRef]

15. Loram, A.; Tratalos, J.; Warren, P.H.; Gaston, K.J. Urban domestic gardens (X): The extent \& structure of the resource in five major cities. Landsc. Ecol. 2007, 22, 601-615. [CrossRef]

16. Mimet, A.; Kerbiriou, C.; Simon, L.; Julien, J.-F.; Raymond, R. Contribution of private gardens to habitat availability, connectivity and conservation of the common pipistrelle in Paris. Landsc. Urban Plan. 2020, 193, 103671. [CrossRef]

17. González-García, A.; Sal, A.G. Private urban greenspaces or 'Patios' as a key element in the urban ecology of tropical central America. Hum. Ecol. 2008, 36, 291-300. [CrossRef]

18. Lindemann-Matthies, P.; Marty, T. Does ecological gardening increase species richness and aesthetic quality of a garden? Biol. Conserv. 2013, 159, 37-44. [CrossRef]

19. Smith, J.; Chapman, A.; Eggleton, P.B. Baseline biodiversity surveys of the soil macrofauna of London's green spaces. Urban Ecosys. 2006, 9, 337-349. [CrossRef]

20. Braschler, B.; Gilgado, J.D.; Zwahlen, V.; Rusterholz, H.-P.; Buchholz, S.; Baur, B. Ground-dwelling invertebrate diversity in domestic gardens along a rural-urban gradient: Landscape characteristics are more important than garden characteristics. PLoS ONE 2020, 15, e0240061. [CrossRef]

21. Barnosky, A.D.; Matzke, N.; Tomiya, S.; Wogan, G.O.U.; Swartz, B.; Quental, T.B.; Marshall, C.; McGuire, J.L.; Lindsey, E.L.; Maguire, K.C.; et al. Has the Earth's sixth mass extinction already arrived? Nature 2011, 471, 51-57. [CrossRef] 
22. Ceballos, G.; Ehrlich, P.R.; Dirzo, R. Biological annihilation via the ongoing sixth mass extinction signaled by vertebrate population losses and declines. Proc. Nat. Acad. Sci. USA 2017, 114, E6089-E6096. [CrossRef] [PubMed]

23. Hallmann, C.A.; Sorg, M.; Jongejans, E.; Siepel, H.; Hofland, N.; Schwan, H.; Stenmans, W.; Müller, A.; Sumser, H.; Hörren, T.; et al. More than 75 percent decline over 27 years in total flying insect biomass in protected areas. PLoS ONE 2017, 12, e0185809. [CrossRef]

24. Didham, R.K.; Barbero, F.; Collins, C.M.; Forister, M.L.; Hassall, C.; Leather, S.R.; Littlewood, N.A.; Menz, M.H.M.; Müller, J.; Packer, L.; et al. Spotlight on insects: Trends, threats and conservation challenges. Insect Conserv. Divers. 2020, 13, 99-102. [CrossRef]

25. Gardiner, T.; Didham, R.K. Glowing, glowing, gone? Monitoring long-term trends in glow-worm numbers in south-east England. Insect Conserv. Divers. 2020, 13, 162-174. [CrossRef]

26. Galluzzi, G.; Eyzaguirre, P.; Negri, V. Home gardens: Neglected hotspots of agro-biodiversity and cultural diversity. Biodivers. Conserv. 2010, 19, 3635-3654. [CrossRef]

27. Gaston, K.J.; Ávila-Jiménez, M.L.; Edmondson, J.L. Review: Managing urban ecosystems for goods and services. J. Appl. Ecol. 2013, 50, 830-840. [CrossRef]

28. Hooykaas, M.J.D.; Schilthuizen, M.; Aten, C.; Hemelaar, E.M.; Albers, C.J.; Smeets, I. Identification skills in biodiversity professionals and laypeople: A gap in species literacy. Biol. Conserv. 2019, 238, 108202. [CrossRef]

29. Goddard, M.A.; Dougill, A.J.; Benton, T.G. Scaling up from gardens: Biodiversity conservation in urban environments. Trends Ecol. Evol. 2010, 25, 90-98. [CrossRef]

30. Matteson, K.C.; Langelotto, G.A. Determinates of inner city butterfly and bee species richness. Urban Ecosyst. 2010, 13, 333-347. [CrossRef]

31. Sperling, C.D.; Lortie, C.J. The importance of urban backgardens on plant and invertebrate recruitment: A field microcosm experiment. Urban Ecosyst. 2010, 13, 223-235. [CrossRef]

32. Gaston, K.J.; Fuller, R.A.; Loram, A.; MacDonald, C.; Power, S.; Dempsey, N. Urban domestic gardens (XI): Variation in urban wildlife gardening in the United Kingdom. Biodiver. Conserv. 2007, 16, 3227-3238. [CrossRef]

33. Kiesling, F.; Manning, C.M. How green is your thumb? Environmental gardening identity and ecological gardening practices. $J$. Environ. Psych. 2010, 30, 315-327. [CrossRef]

34. Lindemann-Matthies, P.; Junge, X.; Matthies, D. The influence of plant diversity on people's perception and aesthetic appreciation of grassland vegetation. Biol. Conserv. 2010, 143, 195-202. [CrossRef]

35. Hoyle, H.; Norton, B.; Dunnett, N.; Richards, J.P.; Russell, J.M.; Warren, P. Plant species or flower colour diversity? Identifying the drivers of public and invertebrate response to designed annual meadows. Landsc. Urban Plan. 2018, 180, 103-113. [CrossRef]

36. Paker, Y.; Yom-Tov, Y.; Alon-Mozes, T.; Barnea, A. The effect of plant richness and urban garden structure on bird species richness, diversity and community structure. Landsc. Urban Plan. 2014, 122, 186-195. [CrossRef]

37. Buchholz, S.; Egerer, M.H. Functional ecology of wild bees in cities: Towards a better understanding of trait-urbanization relationships. Biodivers. Conserv. 2020, 29, 2779-2801. [CrossRef]

38. Egerer, M.; Cecala, J.M.; Cohen, H. Wild bee conservation within urban gardens and nurseries: Effects of local and landscape management. Sustainability 2020, 12, 293. [CrossRef]

39. Smith, R.M.; Warren, P.H.; Thompson, K.; Gaston, K.J. Urban domestic gardens (VI): Environmental correlates of invertebrate species richness. Biodivers. Conserv. 2005, 15, 2415-2438. [CrossRef]

40. Smith, R.M.; Gaston, K.J.; Warren, P.H.; Thompson, K. Urban domestic gardens (VIII): Environmental correlates of invertebrate abundance. Biodivers. Conserv. 2006, 15, 2515-2545. [CrossRef]

41. Wolters, V.; Bengtsson, J.; Zaitsev, A.S. Relationship among the species richness of different taxa. Ecology 2006, 87, 1886-1895. [CrossRef]

42. Shwartz, A.; Turbé, A.; Simon, L.; Julliard, R. Enhancing urban biodiversity and its influence on city-dwellers: An experiment. Biol. Conserv. 2014, 171, 82-90. [CrossRef]

43. Young, C.; Frey, D.; Moretti, M.; Bauer, N. Garden-owner reported habitat heterogeneity predicts plant species richness in urban gardens. Landsc. Urban Plan. 2019, 185, 222-227. [CrossRef]

44. Lauber, K.; Wagner, G.; Gygax, A. Flora Helvetica. Illustrierte Flora der Schweiz; Haupt Verlag: Bern, Switzerland, 2018.

45. Schweiz Bleibt ein Land der Mieter. Available online: https://www.handelszeitung.ch/konjunktur/schweiz-bleibt-ein-land-dermieter-1002502 (accessed on 23 March 2021).

46. Bundesamt für Statistik: Mieter/Eigentümer. Available online: https://www.bfs.admin.ch/bfs/de/home/statistiken/bauwohnungswesen/wohnungen/wohnverhaeltnisse/mieter-eigentuemer.html (accessed on 23 March 2021).

47. Melliger, R.L.; Rusterholz, H.-P.; Baur, B. Ecosystem functioning in cities: Combined effects of urbanisation and forest size on early-stage leaf litter decomposition of European beech (Fagus sylvatica L.). Urban For. Urban Green. 2017, 28, 88-96. [CrossRef]

48. Tresch, S.; Frey, D.; LeBayon, R.-C.; Zanetta, A.; Rasche, F.; Fliessbach, A.; Moretti, M. Litter decomposition driven by soil fauna, plant diversity and soil management in urban gardens. Sci. Total Environ. 2019, 658, 1614-1629. [CrossRef] [PubMed]

49. Meyer, S.; Rusterholz, H.-P.; Salamon, J.-A.; Baur, B. Leaf litter decomposition and litter fauna in urban forests: Effect of the degree of urbanisation and forest size. Pedobiologia 2020, 78, 150609. [CrossRef]

50. Blair, J.M.; Bohlen, P.J.; Freckman, D.W. Soil invertebrates as indicators of soil quality. Methods Assess. Soil Qual. 1997, 49, $273-291$. [CrossRef] 
51. Lavelle, P.; Decaëns, T.; Aubert, M.; Barot, S.; Blouin, M.; Bureau, F.; Margerie, P.; Mora, P.; Rossi, J.P. Soil invertebrates and ecosystem services. Europ. J. Soil Biol. 2006, 42, S3-S15. [CrossRef]

52. Plascencia, M.; Philpott, S.M. Floral abundance, richness, and spatial distribution drive urban garden bee communities. Bull. Entomol. Res. 2017, 107, 658-667. [CrossRef]

53. Wallace, K.J. Classification of ecosystem services: Problems and solutions. Biol. Conserv. 2007, 139, 235-246. [CrossRef]

54. Cooper, N.; Brady, E.; Steen, H.; Bryce, R. Aesthetic and spiritual values of ecosystems: Recognising the ontological and axiological plurality of cultural ecosystem 'services'. Ecosyst. Serv. 2016, 21, 218-229. [CrossRef]

55. Graves, R.A.; Pearson, S.M.; Turner, M.G. Species richness alone does not predict cultural ecosystem service value. Proc. Nat. Acad. Sci. USA 2017, 114, 3774-3779. [CrossRef] [PubMed]

56. Lindemann-Matthies, P.; Bose, E. How many species are there? Public understanding and awareness of biodiversity in Switzerland. Hum. Ecol. 2008, 36, 731-742. [CrossRef]

57. Lindemann-Matthies, P. Wahrnehmung biologischer Vielfalt im Siedlungsraum durch Schweizer Kinder. In Lehr-Und Lernforschung in der Biologiedidaktik; Klee, R., Bayrhuber, H., Eds.; Studienverlag: Innsbruck, Austria, 2002; Volume 1, pp. 117-130. 